\title{
USING HIGH-DENSITY MAGNETIC AND ELECTROMAGNETIC \\ DATA FOR WASTE SITE CHARACTERIZATION \\ A CASE STUDY
}

John R. Cochran,

Sandia National Laboratories

Kim E. Dalton

New Mexico State University

\section{INTRODUCTION}

Magnetometers are frequently used to characterize hazardous waste sites. Due to cost and time considerations, data are typically collected on a coarse grid with nodes on 3 to 6 meter $(\mathrm{m})$ centers. Hardware and software are now available which allow the rapid and cost effective collection of information on a much finer sampling grid. In this paper we present and compare total field magnetometery data collected on $3 \mathrm{~m}$ centers to total field magnetometery data collected on a grid with centers of $0.5 \mathrm{~m}$ or less. We also compare the magnetometery data to time-domain electromagnetic (EM) data collected on a $1 \mathrm{~m}$ by $0.2 \mathrm{~m}$ grid using the recently introduced Geonics Ltd. EM61 metal detector. All three data sets were collected at an abandoned landfill.

\section{WASTE SITE HISTORY}

Radioactive Burial Site No. 11 (RB-11) is located on Kirtland Air Force Base near Albuquerque, New Mexico. This 1 hectare (2.5 acre) landfill was used from 1960 to 1971 and is described as containing nine trenches (Installation Restoration Program ..., 1985). Roughly, these trenches are oriented east-west and are believed to range in depth from 2.5 to $6 \mathrm{~m}$, with $1 \mathrm{~m}$ of cover. No accurate disposal records were kept. The landfill was used primarily for the disposal of contaminated animal carcasses, animal excreta, and associated laboratory wastes. These wastes contain small quantities of hazardous and radioactive materials. Much of the waste is believed to have been contained in $\mathbf{5 5}$ gallon steel drums. The landfill was unmonitored and probably received other types of wastes. An unsubstantiated story reports the burial of a 55 gallon drum of contaminated mercury from the Nevada Test Site (Installation Restoration Program ..., 1985). If the drum exists and it is full, this drum weighs two tons.

\section{WASTE SITE SETTING}

RB-11 is situated on the Sandia-Manzano piedmont plain and is relatively flat. The soils are grasscovered and composed of sandy silt and silty sand. The depth to the water table is approximately $150 \mathrm{~m}$. The two southernmost trenches have narrow asphalt caps and one trench in the middle of site has subsided as much as three feet. The edge of a single drum is exposed near the southern end of the site. There are no fences or known utilities on the site.

\section{GEOPHYSICAL SURVEYS}

Three geophysical surveys were performed. Prior to the first survey, a registered land surveyor used steel rebar to stake the seven corners of the boundary of the landfill. These corners serve as a common reference for each of the geophysical surveys.

The first geophysical survey, a conventional magnetometer survey, was completed in 1988 by an environmental consulting firm (Results of Site Investigation ..., 1988). Referenced to the seven corners of the landfill, measuring tapes were used to lay out a $3 \mathrm{~m}$ by $3 \mathrm{~m}$ grid. Data were collected at each node using an OMNI IV proton procession, total field magnetometer. Magnetic

This work was suppoifed by the Uniled States Department of Energy under Coniract DE-ACO4-94AL85000. 


\section{DISCLAIMER}

Portions of this document may be illegible in electronic image products. Images are produced from the best available original document. 
readings were also recorded several times a day at a base station to determine diurnal variations in the background field values.

During the survey, the locations of visually obvious surface ferrous materials were also recorded. These surface materials included such items as an abandoned jeep and metal warning signs; the reason these materials were not removed prior to the survey is unknown.

The second geophysical survey also used total field magnetometers to collect field data. The site was cleared of surface ferrous materials prior to the second survey. The Naval Research Laboratory (NRL), Geo-Centers Inc. and Sandia National Laboratories conducted a field demonstration of the Multi-sensor Towed Array Detection System (MTADS) at RB-11 in September of 1993 (McDonald, et al., 1994). This field demonstration was conducted using governmentsupplied hardware in conjunction with the Surface Towed Ordnance Locator System (STOLS) marketed by Geo-Centers Inc. of Boston, Massachusetts.

The MTADS consists of an array of seven cesium-vapor magnetometers mounted on a $3 \mathrm{~m}$ wide trailer and towed by a low magnetic signature all-terrain vehicle. Onboard computers sample magnetic field measurements from each Geometrics 822 magnetometer twenty times per second. An eighth, stationary magnetometer at a clean location continuously records diurnal variations in the background field. The onboard computers also log the pitch, roll, direction (fluxgate compass) and position information from a satellite-based global positioning system (GPS). With a static unit and a roving unit, the Trimble 4000 SSE GPS provides real-time location accuracy of $\leq 1 \mathrm{~m}$ at 1 $\mathrm{Hz}$ almost $100 \%$ of the time and $\leq 0.5 \mathrm{~m}$ accuracy $50 \%$ of the time (McDonald, et al., 1993). These accuracies can be improved with post processing.

With the MTADS, the distance between sampling nodes is fixed at $0.5 \mathrm{~m}$ perpendicular to the line of travel and, parallel to the line of travel, varies with vehicle speed. At 11 kilometers/hour $(7$ miles/hour) the effective grid is $0.5 \mathrm{~m}$ by $0.16 \mathrm{~m}$. This rate provides about 60,000 measurements per acre, assuming no overlap. The MTADS surveyed RB- 11 at a rate of about one acre per halfhour. On a good day, the system can collect over $1,000,000$ spatially correlated measurements of the magnetic field.

The third geophysical survey was conducted in June of 1994 using a Geonics Ltd. EM61 high resolution time-domain metal detector (Hyndman, 1994). The EM61 was deployed on a Geonics trailer which is pulled by the operator. Data were collected on parallel lines $1 \mathrm{~m}$ apart; a tic wheel triggered the data acquisition on $0.2 \mathrm{~m}$ intervals to define a sampling grid of $1 \mathrm{~m}$ by $0.2 \mathrm{~m}$.

The EM61 is marketed as an extremely high lateral resolution instrument which can detect a single 55 gallon drum at a depth of more than $3 \mathrm{~m}$ beneath the instrument (EM61 High Sensitivity ..., 1994). As a field test, the EM61 was used to survey a 0.3 hectare $(0.9$ acre) section of RB-11. This 0.3 hectare area was chosen for its isolated deep ferrous targets, and its large ferrous targets exhibiting magnetic signatures with low lateral resolution.

\section{DATA PRESENTATION}

Figure 1 is a contour map of the anomalies in the strength of the magnetic field at RB-11. This map was produced from data collected on $3 \mathrm{~m}$ centers. An average background value of 52,500 gammas was subtracted from the field measurements and the data were contoured using the Spyglass Transform contouring package. As defined in the 1988 report, anomalies attributed to visually obvious surface ferrous materials have been cross-hatched. Individual targets are labeled and the boundaries of the landfill as well as the 0.3 hectare region surveyed with the EM61 are outlined.

Figure 2 is also a contour map of the anomalies in the strength of the magnetic field at RB-11. 
This map was produced from data collected using the MTADS with the magnetometers set at a height of $0.53 \mathrm{~m}$. Time-varying background values were subtracted from the field measurements and the data were then contoured using the Spyglass Transform contouring package.

Figure 3 is a contour map of the data collected in the 0.3 hectare area using the EM61. This image depicts the response of the EM61's main coil subtracted from the response from the focussing coil, in millivolts $(\mathrm{mV})$. This difference was contoured using the Spyglass Transform contouring package. The lowest contour interval is a very sensitive $0.0 \mathrm{mV}$ (the data went down to a $-4 \mathrm{mV}$ ).

\section{DATA ANALYSIS TECHNIQUES}

Magnetometer data are typically analyzed qualitatively (Hempen and Hathaway, 1992). In performing qualitative analysis, the geophysicist mentally merges prior geophysical experience with site specific information. Such interpretations are usually provided in relative terms such as large or small. Qualitative interpretations are not necessarily repeatable as three geophysicists may provide three different interpretations of the same data.

Quantitative analysis of magnetometer data has typically been limited to the two-dimensional matching of profiles. An idealized response profile is compared to the profile obtained from field data, for example (MacLean, et al., 1991). Computers allow three-dimensional model matching, where the spatial distribution of magnetometer values from a field survey are compared to the spatial distribution of values from an assumed target. The best match between the field data and the assumed or modeled target provides the quantitative interpretation of the buried object.

Researchers at New Mexico State University (NMSU) have developed pre-commercial public domain software for analyzing and interpreting data from site surveys, including magnetometer data. The Multi-sensor Analysis Program for Environmental Restoration (MAPER) employs a forward distributed dipole model (McMahon and Mclntire, 1966) to simulate the surface magnetic response due to buried objects in the far field. The distributed dipole model assumes all targets to be threedimensional steel bounding boxes or rectilinear shells with 1 millimeter wall thickness. These simulated rectangles are placed at various subsurface locations and given various sizes; surface responses are simulated based on these target characteristics. This process is repeated until the best match is found between the simulated response and the actual field data. Targets are quantified in terms of location $(x, y, z)$ and dimensions (length, width and thickness). Although not undertaken for this study, MAPER can utilize information from multiple sensors (e.g., GPR and Mag.l; extracting the parameters which each sensor is best at providing.

The magnetometery data collected by the MTADS were analyzed using MAPER. These same magnetometer data were also analyzed using another three-dimensional model matching code employed by the NRL. The NRL/MTADS simulation code uses an iterative least-squares procedure for matching field data to individually modeled dipoles in the far field. This point dipole model assumes that all targets are single points of varying depths and masses. Targets are quantified in terms of location $(x, y, z)$ and mass.

Geonics markets an algorithm for the interpretation of the EM61 data. Such analysis is said to work best for single targets less than a meter wide (which we believe describes many of these targets). The authors do not currently have access to this algorithm.

\section{DATA ANALYSIS}

\section{Qualitative Analysis}

All three data sets contain clusters of data points significantly above background values; all three surveys successfully verify that the area had been used as a landfill. If the purpose of the survey 


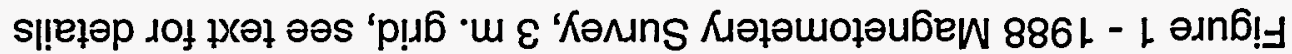

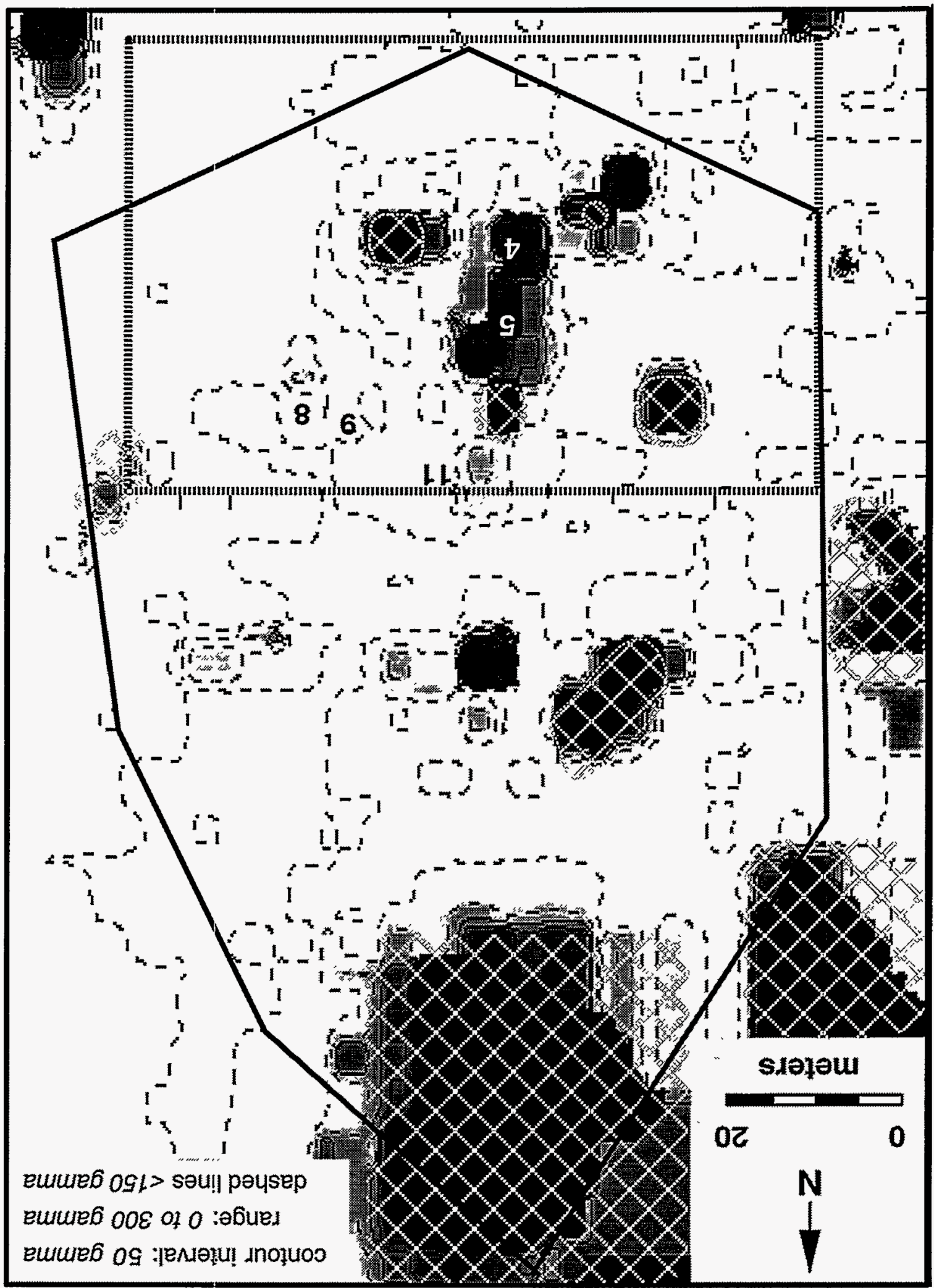




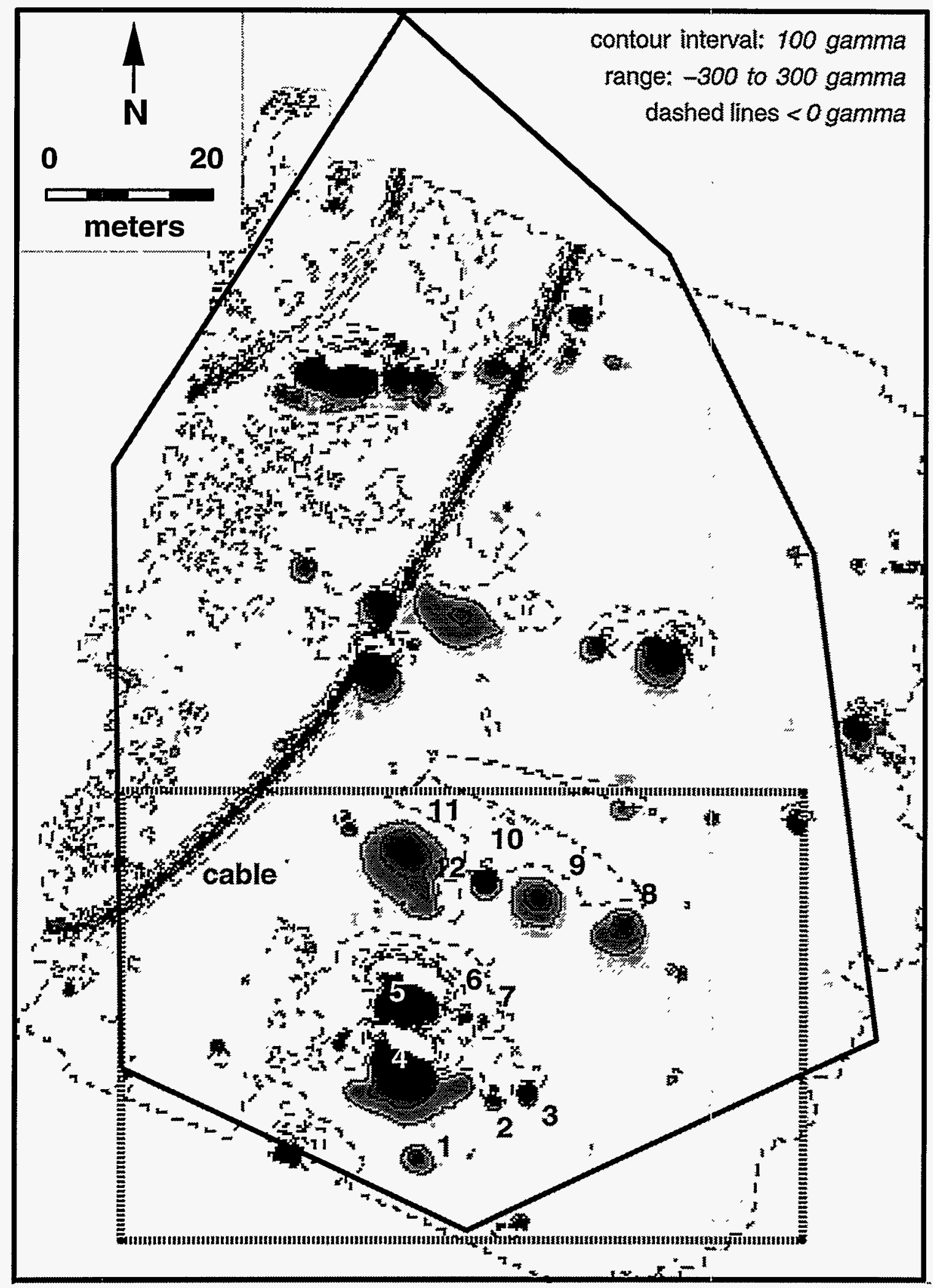

Figure 2 - MTADS Magnetometery Survey, $<0.5 \mathrm{~m}$. grid, see text for details 


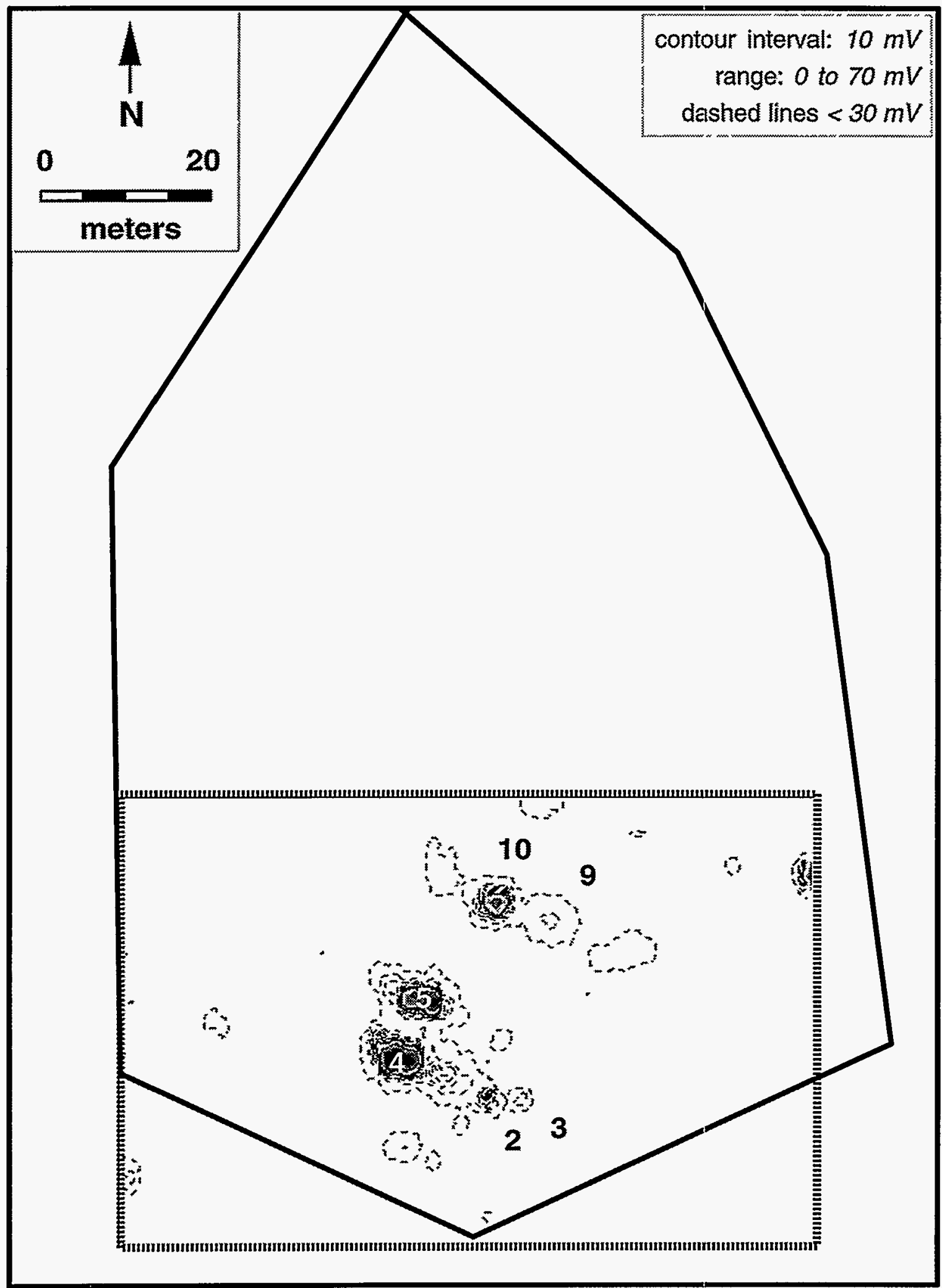

Figure 3 - EM61 Survey, $1.0 \times 0.2 \mathrm{~m}$ grid (focussing - main), see text for details 
was to locate "large" buried objects at RB-11, the MTADS and EM61 surveys were successful; the magnetometer data collected on $3 \mathrm{~m}$ centers would have been successful except the presence of surface ferrous materials disqualifies much of the survey area. The following discussion is limited to the 0.3 hectare area which was surveyed by all three techniques.

The most interesting anomalies detected at RB-11 are the two curved lines that cut across the landfill as shown in Figure 2. These linear anomalies were a mystery when they were first encountered. Some field research revealed the presence of electrical cables, about two centimeters in diameter and about $0.8 \mathrm{~m}$ deep. These non-ferrous cables are apparently the undocumented remains of a military experiment. The cables are not energized and the magnetometers apparently detected some type of "earth-induced" electromagnetic field. Neither the conventional magnetometer survey nor the EM61 detected these buried cables.

The 1988 conventional survey (Figure 1) and the MTADS survey (Figure 2) were "identical" except for the sampling grid. The finer sampling grid provides higher resolution images of the buried wastes and allowed the detection of more burials than either of the other two surveys. Both of these conclusions are visually intuitive.

Without numerical analysis of the lateral edges of anomalies, the EM61 provided the best definition of the edges of anomalies, as expected. Unfortunately, the instrument was not sensitive enough to detect the electrical cable or the targets 11 (T11) and T12 (it is not clear why the EM61 did not detect T12). Very small responses, $0.0 \mathrm{mV}$, were measured in the vicinity of T1, T6, T7 and T8. Without prior knowledge (e.g., Figure 2) these responses would not have been identified as burials by most interpreters.

\section{Quantitative Analysis}

The MTADS data was numerically interpreted using both the MAPER algorithm and the MTADS algorithm. Table 1 presents the results of this analysis. Interpretation of the conventional magnetometer data was not possible due to the sparsity of the data (discussed later); this is reflected in the shape of the contoured magnetic anomalies.

Table 1

Quantitative Analysis of MTADS Data

\begin{tabular}{||c|c|c|c|c|l|c||}
\hline Target & $\begin{array}{c}\text { MTADS } \\
\text { depth }\end{array}$ & $\begin{array}{c}\text { MTADS } \\
\text { size }^{2}\end{array}$ & $\begin{array}{c}\text { MAPER } \\
\text { depth }\end{array}$ & $\begin{array}{l}\text { MAPER shell } \\
\text { dimensions } \\
\text { Lx W } \times \text { Thickness }\end{array}$ & $\begin{array}{c}\text { MAPER } \\
\text { mass } \\
\mathrm{kg}\end{array}$ \\
\hline 1 & 1.7 & $\mathrm{lg}$ & & 1.4 & $0.5 \times 0.5 \times 0.3$ & 10 \\
\hline 2 & 0.3 & $\mathrm{sm}$ & & 0.5 & $0.4 \times 0.8 \times 0.1$ & 11 \\
\hline 3 & 0.6 & med & & 1.1 & $0.8 \times 0.8 \times 0.2$ & 23 \\
\hline 4 & 2.2 & $?$ & & 1.5 & $1.4 \times 4.7 \times 1$ & 225 \\
\hline 5 & 0 & drum & & 0 & exposed drum & - \\
\hline 6 & 0.5 & $\mathrm{sm}$ & & 2.1 & $1.0 \times 1.0 \times 0.3$ & 36 \\
\hline 7 & 0.3 & $\mathrm{sm}$ & & 1.0 & $0.5 \times 1.0 \times 0.3$ & 18 \\
\hline 8 & 2.5 & $\mathrm{lg}$ & & 2.5 & $0.4 \times 1.6 \times 1.0$ & 27 \\
\hline
\end{tabular}




\begin{tabular}{|c|c|c|c|c|c|c||}
\hline 9 & 3.4 & $\lg$ & & 2.9 & $0.3 \times 1.3 \times 1.4$ & 20 \\
\hline 10 & 1.0 & $\lg$ & & 1.3 & $0.3 \times 1.3 \times 0.5$ & 15 \\
\hline 11 & 3.8 & $\lg$ & & 3.7 & $1.0 \times 2.0 \times 0.7$ & 74 \\
\hline 12 & 1.5 & $\lg$ & & 1.8 & $3.0 \times 2.0 \times 0.5$ & 213 \\
\hline
\end{tabular}

Footnotes 1. all lengths are in meters. 2. small is $<60 \mathrm{~mm}$ mortar, medium is $105 \mathrm{~mm}, 45 \mathrm{~kg}$, and $\mathrm{Ig}$ is $>114 \mathrm{~kg}, 3$. depth to center of mass

Missing from this table is $x, y$ location of each anomaly. MTADS and MAPER programs automatically identify the location of each anomaly in the appropriate coordinate system. For example, $\mathrm{T} 1$ is located at $35^{\circ} 0.40737$ latitude and $106^{\circ} 31.10213$ longitude (NAD 83). Because of the limited space for text, the locations of all 12 targets are not printed here. The ability to automatically generate target maps with coordinates for each target is an advantage of these two algorithms over generic contouring packages.

None of these targets have been excavated; therefore, predicted target characteristics can not be compared to actual target characteristics. So how good is the numerical analysis? In an unpublished study conducted at Twentynine Palms Marine Corps Base, the NRL found the point dipole algorithm to be very accurate for analyzing buried ordnance. Several observations can be made here which support the numerical analysis. The wastes that were analyzed as being buried deeper than $3 \mathrm{~m}$ (T9 and T11) are both in the same trench. Also, the large burial (T11) that was analyzed as being $3.8 \mathrm{~m}$ deep was undetected by the EM61 (why the EM61 did not detect the shallower T12 is unknown). Other tests are being conducted to test the validity of these algorithms.

Numerical analysis does provide a number of very important advantages over qualitative analysis. First, targets can be quantified. Ambiguous descriptions like "large and fairly deep burial" are replaced with quantitative descriptions like " $300 \mathrm{~kg}$ ferrous object buried at $2.5 \mathrm{~m}$ ". Threshold criteria (e.g., excavate only targets greater than $10 \mathrm{~kg}$ ) can then be applied to site cleanup. Second, numerical analysis allows the user to interpret or "see" individual targets instead of the magnetic dipole expression of targets. At this landfill, the ability to see individual targets puts magnetometery data and EM61 data on even footing, with both providing discrete target locations. Third, and very important for quality control, numerical analysis can be reliably repeated. Finally, numerical analysis is an important tool in the data interpretation tool chest; numerical analysis should never be viewed as the only tool in the tool chest.

\section{COMPARISON BETWEEN TECHNIQUES}

Figure 4 is an $8 \mathrm{~m}$ by $20 \mathrm{~m}$ area of the landfill capturing targets 9 through 12 . Figure 4 is a presentation of the raw or uninterpolated data from each of the three surveys where individual data points are enlarged and given false color related to the field readings. The apparent shifting of data in the top image is probably the result of inaccuracies in locating the original grid in 1988 .

Many of the advantages of collecting high density magnetometer data are visually obvious. First, small ferrous targets, like T10 can be detected. Second, the actual shape of anomalies in the magnetic field are measured, not created by the contouring package. Capturing the spatial distribution of magnetic values allows more accurate numerical analysis of burials. Third, total field magnetometers are more sensitive (i.e., detect deeper ferrous targets) than the EM61. 
1988 Magnetometer Survey

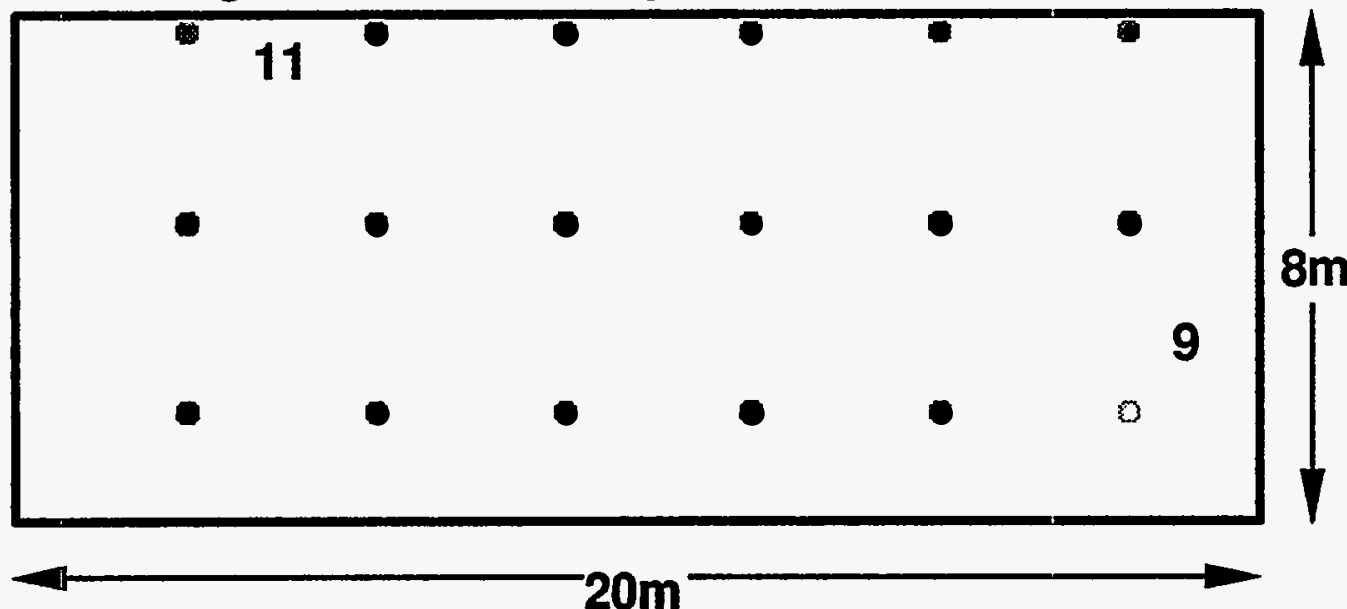

MTADS Magnetometer Survey

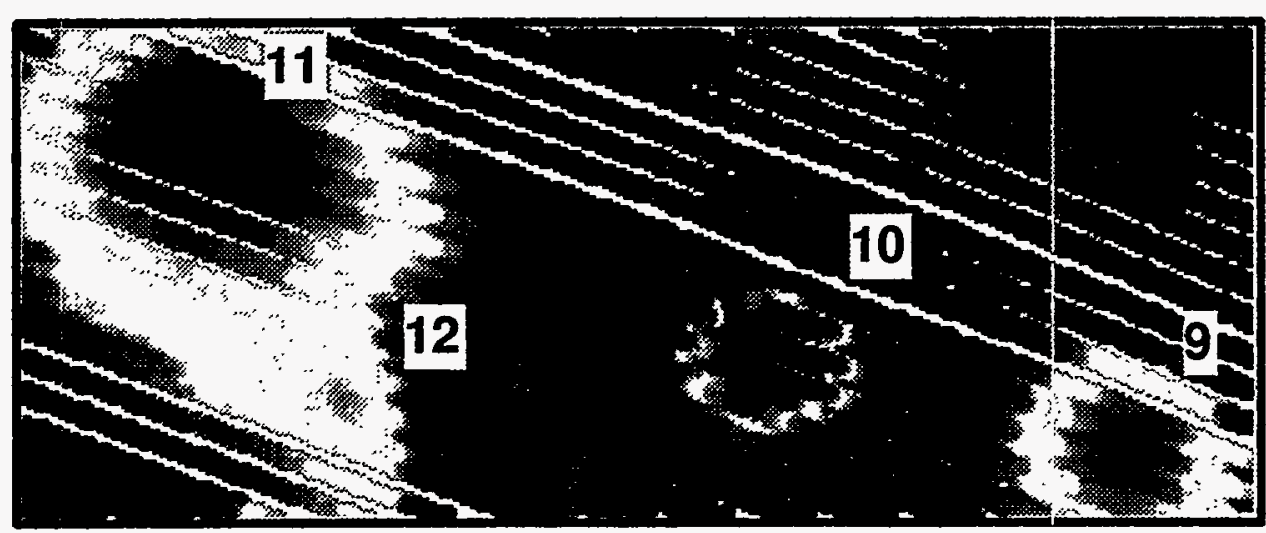

\section{EM61 Survey}

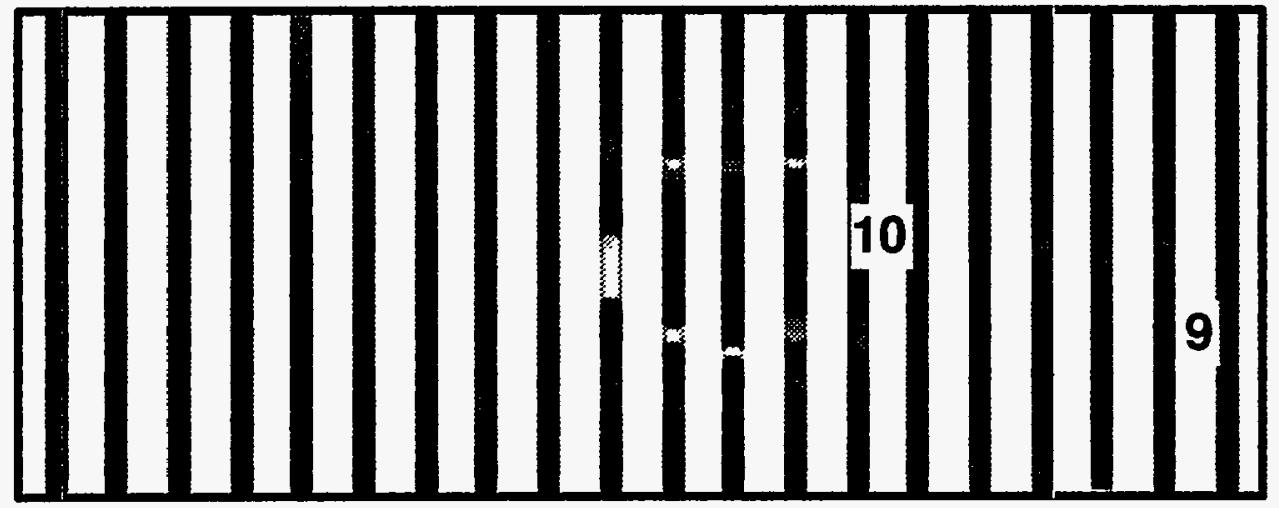

Figure 4 - Sample of Uninterpolated Data, All Three Surveys 


\section{RECOMMENDATIONS AND CONCLUSIONS}

Several areas of additional work were identified. Determining the nature of the "earth-induced" electromagnetic field generated in the buried cables would be interesting. Numerical analysis of the EM61 data and a comparison of that analysis to the magnetometery data would be useful. Finally, additional research needs to be conducted to "validate" the numerical codes for analyzing the magnetic responses from extended targets (i.e., trench burials).

At this landfill, the magnetometer data collected on a fine grid provided several clear advantages over both conventional magnetometery data and EM61 data. First, smaller ferrous targets can be detected (e.g., T10). Second, the actual shape of anomalies in the magnetic field is measured, not created by the contouring package. Capturing the spatial distribution of magnetic values allows better numerical analysis of burials. Finally, total field magnetometers can detect deeper targets than the EM61. Based on this survey, the EM61 may not be as sensitive as indicated in the marketing literature. In summary, for characterizing landfills, magnetometery data should be collected on $1 \mathrm{~m}$ or finer grid.

\section{ACKNOWLEDGEMENTS}

The authors would like to thank Dr. Jim McDonald, NRL; Robbie Robertson, Hughes Associates; Dick Russell, Geo-Centers Inc. and Dr. Edward Hensel, NMSU for their support. This team effort was funded by the Department of Energy, Office of Technology Development, through Sandia's Mixed Waste Landfill Integrated Demonstration Program and the Naval Facilities Command, Shoreside Environmental RDT\&E Program.

\section{REFERENCES}

EM 61 High Sensitivity Metal Detector Operating Manual, April 1994: Geonics Limited. Hempen, G.L. and Hatheway, A.W., 1992, Geophysical Methods for Hazardous Waste Site Characterization: Association of Engineering Geologists, Special Publication No. 3, Association of Engineering Geologists, Sudbury, Massachusetts.

Hyndman, D. A., June 1994, EM-61 High Resolution Electromagnetic Survey RB-11 Landfill, Kirtland Air Force Base, Albuquerque New Mexico: Sunbelt Geophysics, Albuquerque, NM.

Installation Restoration Program, Phase II - Confirmation/Quantification, Stage 1, Kirtland AFB, New Mexico, March 1985, prepared for USAF, Headquarters Military Air Lift Command (HQ MAC/SGPB), Scott AFB, Illinois and USAF Occupational and Environmental Health Laboratory, Brooks AFB, Texas: Prepared by Science Applications International Corporation (SAIC 2-827-06-351-33), Albuquerque NM.

MacLean, H. D., Dickerson, J.W., Hasbrouch, J.C. and Cotter, E.T., 1991, Geophysical Surveys for Underground Storage Tank Locations, Hickman Air Force Base Hawaii: a Case Study, Symposium on the Application of Geophysics to Engineering and Environmental Problems: Society of Engineering and Mineral Exploration Geophysicists.

McDonald, J. R., Nelson, H. H., and Robertson, R., July 1993, Microwave and Differential GPS Navigation Systems: Field Performance Tests: Naval Research Laboratory, NRL/PU/611093-244.

McDonald, J. R., Robertson, R. and Cochran, J.R., May 1994, Results of a Magnetometer Towed Array Survey and Sub-System Testing at Site RB-11, Kirtland Air Force Base, Albuquerque NM.: Naval Research Laboratory, NRL/PU/6110-94-257.

McMahon, R.F., and McIntire, R.E., October 1966, Magnetic Anomaly Computations: Magan 360 Magnetic Anomaly computations for IBM System 360/Chevron Oil Company Western Division, Exploratory Geophysics, Denver CO, 16 pp.

Results of Site Investigation and Magnetics Survey of the RB-11 Radioactive Burial Site Kirtland Air Force Base, New Mexico, March 1988: IT Corporation, Albuquerque, NM. 


\section{DISCLAIMER}

This report was prepared as an account of work sponsored by an agency of the United States Government. Neither the United States Government nor any agency thereof, nor any of their employees, makes any warranty, express or implied, or assumes any legal liability or responsibility for the accuracy, completeness, or usefulness of any information, apparatus, product, or process disclosed, or represents that its use would not infringe privately owned rights. Reference herein to any specific commercial product, process, or service by trade name, trademark, manufacturer, or otherwise does not necessarily constitute or imply its endorsement, recommendation, or favoring by the United States Government or any agency thereof. The views and opinions of authors expressed herein do not necessarily state or reflect those of the United States Government or any agency thereof. 